Fetal Diagnosis and Therapy
Fetal Diagn Ther 2017;41:81-88

DOI: $10.1159 / 000453062$
Received: May 19, 2016

Accepted after revision: November 3, 2016

Published online: December 8, 2016

\title{
Sildenafil in Pregnancy: A Systematic Review of Maternal Tolerance and Obstetric and Perinatal Outcomes
}

\author{
Liam Dunn $^{\mathrm{a}}$ Ristan Greer ${ }^{\mathrm{a}}$ Vicki Flenady ${ }^{\mathrm{a}}$ Sailesh Kumar ${ }^{\mathrm{a}-\mathrm{c}}$ \\ ${ }^{a}$ Mater Research Institute, University of Queensland, ${ }^{\mathrm{b}}$ Mater Mothers' Hospital, and 'School of Medicine, University \\ of Queensland, Brisbane, QLD, Australia
}

\section{Keywords}

Sildenafil citrate · Placental insufficiency - Fetal hypoxia .

Fetal therapies · Pregnancy

\begin{abstract}
Introduction: This systematic review evaluates maternal tolerance and obstetric and perinatal outcomes following sildenafil citrate (SC) use in human pregnancy. Data Sources: Scopus, PubMed, Cochrane Library, Web of Science, Embase, and Google Scholar were searched. Relevant full-text studies including case series and reports in English were included. Publications were excluded if the pregnancy was terminated or if SC was used only at conception. $\boldsymbol{R e}$ sults: Sixteen studies were included $(n=165)$. Indications for use and outcomes were variably reported. Maternal outcomes reported were headache $(45.8 \%, 49 / 107)$, visual disturbances $(17.3 \%, 14 / 81)$, dyspepsia/epigastric pain (15.8\%, $15 / 95)$, and hypotension $(0 \%, 0 / 39)$. There were more caesarean $(83.3 \%, 55 / 66)$ than vaginal deliveries $(16.7 \%, 11 / 66)$ and postpartum haemorrhage occurred in $3.9 \%(3 / 76)$ of women exposed to SC. Neonatal outcomes including nursery admission (67.3\%,35/52), Apgar scores $<7$ at $5 \mathrm{~min}$ $(7.1 \%, 4 / 56)$, and cord arterial $\mathrm{pH}<7.1(0 \%, 0 / 17)$ were reported. Stillbirths $(4.3 \%, 3 / 69)$ and neonatal deaths $(3.9 \%$,
\end{abstract}

\section{KARGER}

๑) 2016 S. Karger AG, Basel

E-Mail karger@karger.com

www.karger.com/fdt
5/129) were comparable to SC-naïve groups. There were no congenital malformations $(0 \%, 0 / 35)$. Conclusions: Despite limited data, overall there does not appear to be any severe adverse maternal side effects nor any increase in the rate of stillbirths, neonatal deaths, or congenital anomalies attributed to SC.

(c) 2016 S. Karger AG, Basel

\section{Background}

Sildenafil citrate (SC) is a phosphodiesterase-5 (PDE5 ) inhibitor. It acts by preventing the degradation of the second messenger cyclic guanosine $3^{\prime}, 5^{\prime}$-monophosphate by the enzyme PDE-5. This results in increased nitric oxide production and consequent vascular smooth muscle relaxation and an increase in vasodilation [1]. Due to its preferential vasodilatory effects on pelvic vasculature, SC is now a well-established treatment for erectile dysfunction in males [2] and this remains its most common indication for use. It has also been trialled in children [3-5] and pregnant women [6-8] with pulmonary hypertension $(\mathrm{PH})$.

The vasodilatory effects of SC also manifest on uterine and myometrial vessels [9-11], which results in increased 
uterine flow $[12,13]$ and endometrial thickening $[11,14]$ putatively promoting an increase in fetal weight [15]. Its use in human pregnancy has largely been restricted to a few specific maternal indications, including severe $\mathrm{PH}$ [16-22] or preeclampsia (PET) $[23,24]$, and as an adjunct to presumed inadequate uteroplacental perfusion $[13,25]$ and severe early-onset fetal growth restriction (FGR) [12, 26-29]. This in turn has led to a current ongoing multicentre randomised controlled trial (RCT) of SC for the treatment of severe FGR [30].

To date, the use of SC in human pregnancy has been confined to relatively small RCTs and case series and reports.

\section{Objective}

There is increasing interest in, and use of, $\mathrm{SC}$ as a therapeutic option for PH, PET, and FGR. The purpose of this systematic review was to collate the current evidence in relation to maternal tolerance and side effects, and obstetric and perinatal outcomes following the use of SC in human pregnancy.

\section{Data Sources}

An online database search for all relevant publications from the past 30 years was undertaken by the authors and institutional research librarian in July 2016. Databases included Scopus, PubMed, Cochrane Library, Web of Science, Embase, and Google Scholar. Keywords and $\mathrm{MeSH}$ terms used included: "sildenafil citrate", "Viagra $^{\circledR}$ ", "phosphodiesterase-5 inhibitor", "pregnancy", "labor", "preeclampsia", "hypertension", "fetal growth restriction", "pulmonary hypertension", "mode of delivery", "hypotension", "haemorrhage", "visual disturbances", "fetus", "newborn", "neonate", "Apgar", "perinatal death". All publications reporting the use of SC in human pregnancy with full text or abstract written in English and available electronically were collated for review.

The population of interest was pregnant women who were exposed to SC compared to no SC or placebo. All titles and abstracts were independently reviewed by authors L.D. and S.K. to exclude duplicated and ineligible manuscripts. Systematic and expert reviews, abstracts, book chapters, opinion pieces, and guidelines were excluded. Publications were also excluded if the reported pregnancy was terminated or if SC was only used during peri-conception and not during pregnancy. A manual

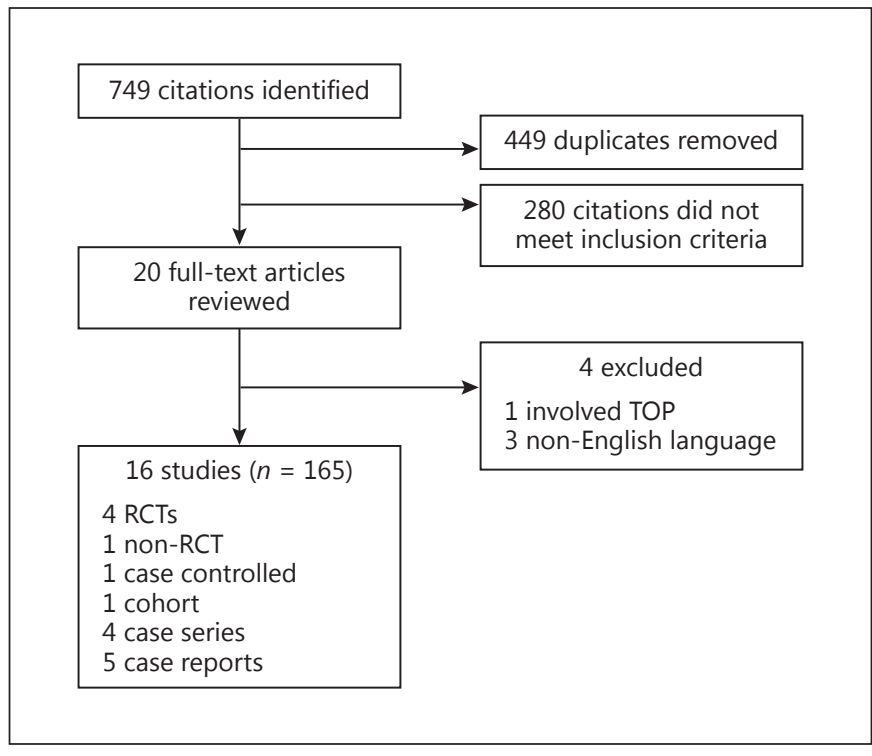

Fig. 1. Selection of studies. TOP, termination of pregnancy; RCTs, randomized controlled trials.

search of the reference lists of primary articles was carried out to identify relevant articles not captured in the initial electronic searches. Where possible, authors were contacted for clarification of reported data.

Relevant standards of reporting for each publication type [31-33] were referenced as was the Preferred Reporting for Systematic Reviews and Meta-Analyses statement [34]. Case series [35] and case reports [31] were critically evaluated and included if the outcomes of interest were detailed and provided relevant information on the topic. This was a pragmatic decision given the rarity of SC use in pregnancy.

\section{Results}

The flow of identification of relevant studies is shown in Figure 1. Seven hundred and forty-nine publications were initially retrieved using the abovementioned methodology. After all abstracts were screened, 20 full-text articles were reviewed. Three of these publications were excluded because full-text versions were not accessible in English [36-38] and one case report was excluded because it involved a therapeutic second-trimester termination of pregnancy [39].

The final number of publications included for analysis in this systematic review was 16 , comprising 165 preg- 
Table 1. Summary of included studies

\begin{tabular}{|c|c|c|c|c|c|c|c|c|}
\hline First author, year [Ref.] & Publication & Country & $\begin{array}{l}\text { Indica- } \\
\text { tion }\end{array}$ & $\begin{array}{l}\text { Cohort } \\
\text { size }\end{array}$ & $\begin{array}{l}\text { Maternal } \\
\text { age, years }\end{array}$ & $\mathrm{SC}$ regimen & $\begin{array}{l}\text { SC duration, } \\
\text { days }\end{array}$ & $\begin{array}{l}\text { GA at SC } \\
\text { start, weeks }\end{array}$ \\
\hline Trapani, 2016 [24] & $\mathrm{RCT}$ & Brazil & PET & 50 & $25.3 \pm 5.4$ & 50 mg PO 8-hourly & $14.4^{\mathrm{b}}$ & $29.1 \pm 2.1$ \\
\hline Dastjerdi, 2012 [12] & RCT & Iran & FGR & 14 & $25.6 \pm 1.5$ & $50 \mathrm{mg}$ PO once & 1 & $35 \pm 2$ \\
\hline Samangaya, 2009 [23] & RCT & UK & PET & 17 & $28(24-34)$ & 20-80 mg PO 8-hourly & $4[1-15]$ & $31.4(26.6-32.5)$ \\
\hline El-Far, 2014 [25] & Non-RCT & Egypt & URSM & 40 & * & 25 mg PV 6-8-hourly & 13 or 24 & $<13$ \\
\hline Duarte, 2013 [17] & Case series & USA & $\mathrm{PH}$ & 4 & $23.5[19-34]$ & $20-50 \mathrm{mg}$ PO & $66.5[49-196]$ & $25.5[6-29]$ \\
\hline Kiely, $2010[18]$ & Case series & UK & $\mathrm{PH}$ & 3 & $23[21-38]$ & 25 mg PO 8-hourly & $7[7-238]$ & $31[0-33]$ \\
\hline Goland, 2010 [19] & Case series & USA & $\mathrm{PH}$ & 2 & $21 ; 30$ & 25-50 mg PO 8-hourly & $7 ; 31$ & $36 ; 32$ \\
\hline El-Far, 2009 [13] & Case series & Egypt & URSM & 4 & $27[22-30]$ & 25 mg PV 6-hourly & $23[20-24]$ & $9[6-11]$ \\
\hline Panda, 2014 [27] & Case report & India & FGR & 1 & 32 & 50 mg PO 8-12-hourly & 21 & 26.6 \\
\hline Lin, 2012 [28] & Case report & Taiwan & FGR & 1 & 30 & 25 mg PO 8-hourly & 48 & 26 \\
\hline
\end{tabular}

Data are mean \pm standard deviation, median (interquartile range), or median [range]. ${ }^{*}$ Maternal age (median [range]) reported for each SC cohort: 27 years [19-35] and 26.5 years [20-33]. ${ }^{a}$ Frequency not reported. ${ }^{b}$ Average duration of SC dosing. ${ }^{c}$ SC 50 mg PO daily from conception until 9 weeks and then recommenced at 31 weeks until delivery at 36 weeks. RCT, randomised controlled trial; Non-RCT, non-randomised controlled trial; SC, sildenafil citrate; PET, preeclampsia; FGR, fetal growth restriction; URSM, unexplained recurrent spontaneous miscarriage; PH, pulmonary hypertension; NR, not reported; PO, per oral; PV, per vaginal; GA, gestational age.

nancies in total. These included 4 RCTs, 1 non-RCT, 1 case-controlled, 1 cohort, 4 case series, and 5 case reports (Table 1). Data on the number of participants exposed to SC, gestational age at exposure to SC, indication for and duration of SC use, as well as dosage and route of administration were collected (Table 1). Outcomes examined included maternal (hypotension, visual disturbances, headache, dyspepsia/epigastric pain) (Table 2), obstetric (mode of delivery, postpartum haemorrhage), and perinatal (gestational age at delivery, birthweight, Apgar score, acidosis at birth [cord artery $\mathrm{pH}<7.1$ ], nursery admission, congenital anomalies, stillbirth, and neonatal death) (Table 3). Not all outcomes relevant to this review were reported by each publication.

\section{Hypotension}

Nine studies [13, 17, 19, 20, 22-24, 26, 29] (79 pregnancies) reported information on maternal blood pressure. Three RCTs $[23,24,29]$ reported significant reductions in maternal blood pressure amongst women with PET. Only one [23] of these RCTs in addition to other studies [13,17, 19, 20, 22, 26], however, reported sufficient data to estimate the overall rate of hypotension $(0 \%$, $0 / 39)$.

\section{Visual Disturbance}

Of the 4 studies $[13,23,24,26]$ (81 pregnancies) that reported on visual disturbances, 2 RCTs $[23,24]$ detailed 14 women $(17.3 \%, 14 / 81)$ who were affected by visual disturbances. However, in both of these RCTs, visual disturbances occurred at similar rates to those in the placebo groups and no participant withdrew because of visual disturbances $[23,24]$.

\section{Headache}

The overall rate of headache was $45.8 \%(49 / 107)$ as documented in 6 studies [12, 13, 23, 24, 26, 29]. This appeared to be the more commonly reported maternal symptom. In 4 RCTs $[12,23,24,29]$, rates of headache were comparable between the SC and the control groups.

\section{Dyspepsia and Epigastric Pain}

In 5 studies [12, 13, 23, 24, 26], the overall rate of dyspepsia and epigastric pain was $15.8 \%$ (15/95). Three RCTs $[12,23,24]$ did not report any difference in rates of dyspepsia or epigastric pain between SC and control groups.

\section{Other Maternal Symptoms}

Information about other maternal symptoms in 147 pregnancies was obtainable from 7 studies $[12,13,23-26$, 
Table 2. Maternal tolerance outcomes following sildenafil citrate use in pregnancy

\begin{tabular}{|c|c|c|c|c|c|}
\hline First author, year [Ref.] & Indication & Hypotension & Visual disturbances & Headache & Dyspepsia/epigastric pain \\
\hline Overall rate (\%) & - & $0 / 39(0)$ & 14/81 (17.3) & 49/107 (45.8) & $15 / 95(15.8)$ \\
\hline Trapani, 2016 [24] & PET & NR & $10 / 50$ & $32 / 50$ & $10 / 50$ \\
\hline Trapani, 2016 [29] & FGR & NR & NR & $2 / 12$ & NR \\
\hline Dastjerdi, 2012 [12] & FGR & NR & NR & $1 / 14$ & $0 / 14$ \\
\hline Samangaya, 2009 [23] & PET & $0 / 17$ & $4 / 17$ & $14 / 17$ & $5 / 17$ \\
\hline El-Far, $2014[25]$ & URSM & $*$ & * & $*$ & $*$ \\
\hline von Dadelszen, 2011 [26] & FGR & $0 / 10^{\mathrm{a}}$ & $0 / 10^{\mathrm{a}}$ & $0 / 10^{\mathrm{a}}$ & $0 / 10^{\mathrm{a}}$ \\
\hline Subbaiah, 2013 [16] & $\mathrm{PH}$ & NR & NR & NR & NR \\
\hline Duarte, 2013 [17] & $\mathrm{PH}$ & $0 / 4$ & NR & NR & NR \\
\hline Kiely, $2010[18]$ & $\mathrm{PH}$ & NR & NR & NR & NR \\
\hline Goland, 2010 [19] & PH & $0 / 2^{\mathrm{b}}$ & NR & NR & NR \\
\hline El-Far, 2009 [13] & URSM & $0 / 4^{\mathrm{c}}$ & $0 / 4^{c}$ & $0 / 4^{\mathrm{c}}$ & $0 / 4^{c}$ \\
\hline Panda, 2014 [27] & FGR & NR & NR & NR & NR \\
\hline Lin, $2012[28]$ & FGR & NR & NR & NR & NR \\
\hline $\mathrm{Ng}, 2012[20]$ & $\mathrm{PH}$ & $0 / 1$ & NR & NR & NR \\
\hline Molelekwa, 2005 [21] & $\mathrm{PH}$ & NR & NR & NR & NR \\
\hline Lacassie, 2004 [22] & $\mathrm{PH}$ & $0 / 1$ & NR & NR & NR \\
\hline
\end{tabular}

PET, preeclampsia; FGR, fetal growth restriction; URSM, unexplained recurrent spontaneous miscarriage; PH, pulmonary hypertension; NR, not reported. * "Commonly recorded adverse effects" reported in 27/40 (67.5\%) but no "serious adverse effects". ${ }^{\text {a No }}$ "adverse maternal side effects". b "Uneventful" delivery and "stable" postpartum. " "No complications or side effects" from antenatal SC.

Table 3. Obstetric and perinatal outcomes following sildenafil citrate use in pregnancy

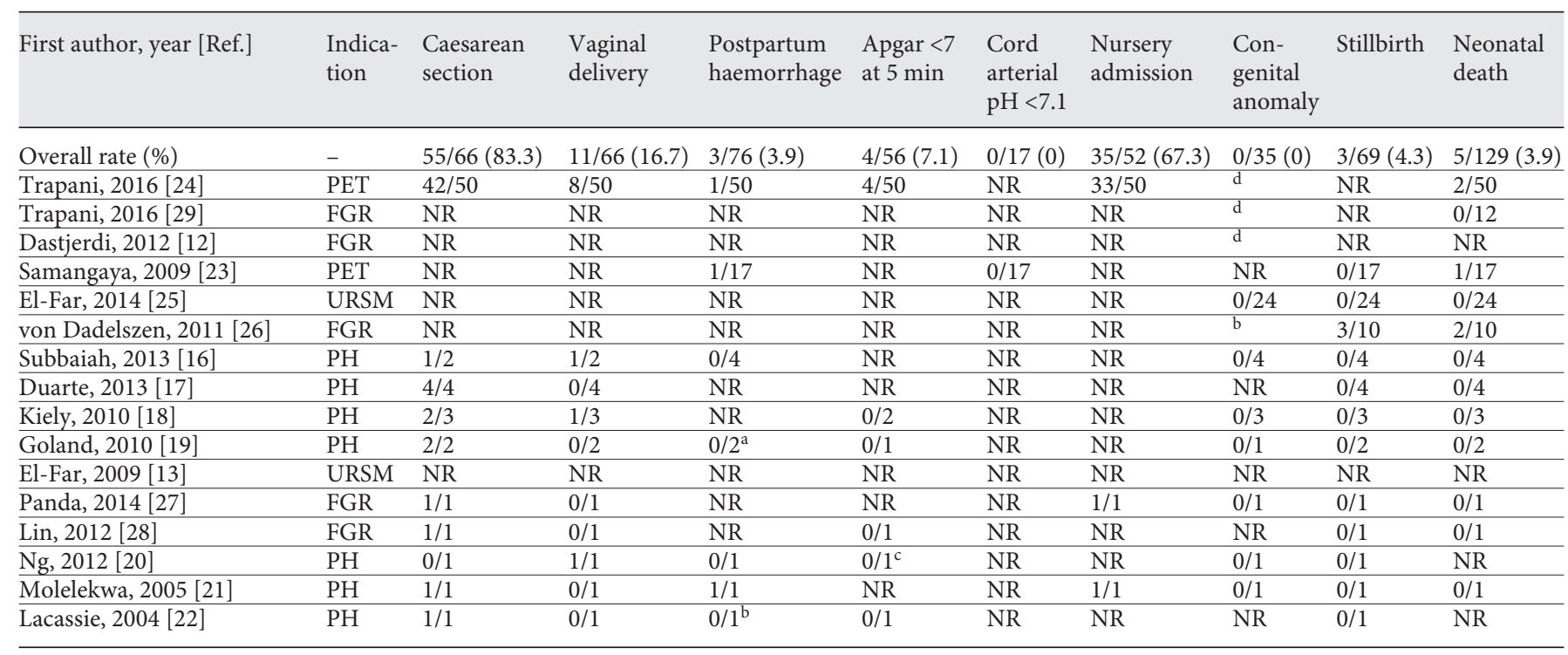

PET, preeclampsia; FGR, fetal growth restriction; URSM, unexplained recurrent spontaneous miscarriage; PH, pulmonary hypertension; NR, not reported. a "Uneventful" delivery and "stable" postpartum. " "Uneventful" delivery. " "Baby was healthy with an Apgar score of 9" (time not specified) d Exclusion criteria in these studies. 
29] with reassuring outcomes. Vomiting, dizziness, diarrhoea, neurological symptoms, facial flushing, and arthralgia and myalgia were reported by the 4 RCTs $[12,23$, 24,29 ] with similar rates in both the SC and control groups. Additional information on maternal tolerance to SC was reported in 3 other studies [13, 25, 26]. The specific nature of the side effects and their rates of occurrence in these studies, however, were not consistently reported, though none were described as severe $[13,25,26]$.

\section{Mode of Delivery}

Ten studies [16-22, 24, 27, 28] reported the modes of delivery for 66 pregnancies. The overall rates for caesarean (CS) and vaginal births (including instrumental births) were $83.3 \%$ (55/66) and $16.7 \%$ (11/66), respectively. Indication for delivery was not consistently reported across all studies, however; $16.4 \%(9 / 55)$ of CS were performed for severe PH [16-19], 3.6\% (2/55) were performed for FGR $[27,28]$, and $3.6 \%(2 / 55)$ were performed for overlapping serious maternal and fetal indications $[21,22]$.

\section{Postpartum Haemorrhage}

The overall postpartum haemorrhage rate, reported in 7 studies $[16,19-24]$, was $3.9 \%(3 / 76)$. In 2 of the larger RCTs $[23,24]$, postpartum haemorrhage rates were similar in both the SC and the control groups.

\section{Gestational Age at Delivery and Birthweight}

The gestational age at birth following antenatal SC exposure varied from 27 weeks [26] to 37 weeks [19], as reported for 76 babies in 11 studies [16-22, 24, 26-28]. Birthweights for 77 babies were reported across 9 publications $[16,18,19,21-24,27,28]$. The minimum and maximum reported birthweights were $553 \mathrm{~g}$ [23] and 2,480 g [23], respectively. However, there was incomplete data regarding the range of birthweights and corresponding gestational age at birth for the other studies.

\section{Apgar $<7$ at $5 \mathrm{~min}$}

Six publications [18-20, 22, 24, 28] reported Apgar scores of 56 babies. Of these, there were 4 cases of Apgar scores $<7$ at $5 \mathrm{~min}(7.1 \%, 4 / 56)$ that were all reported in 1 RCT [24]. The same RCT also reported a lower rate of Apgar scores $<7$ at $5 \mathrm{~min}$ in the SC group compared to the placebo group ( $8 \%, 4 / 50$ vs. $12 \%, 6 / 50)$ [24].

\section{Cord Arterial $p H<7.1$}

Only one study reported cord arterial $\mathrm{pH}$ in babies born to mothers who had received SC antenatally [23]. None of the 17 babies in the SC cohort had cord arterial $\mathrm{pH}<7.1$.
Furthermore, there were no clinically important differences in the median cord arterial pH of the SC (7.25, range: 7.177.31) and the placebo (7.29, range: 7.26-7.3) groups [23].

\section{Admission to Neonatal Intensive Care Unit}

Thirty-five babies $(67.3 \%, 35 / 52)$ were admitted to the neonatal intensive care unit, reported in 1 RCT [24] and in 2 case reports $[21,27]$. Although not powered to detect differences in neonatal outcomes, Trapani et al. [24] observed a lower incidence of neonatal intensive care unit admissions amongst babies born in the SC cohort compared to placebo (66\%, 33/50 vs. $74 \%, 37 / 50)$. The indications for admission were not specified, though overall rates of other important neonatal outcomes (infection, intraventricular haemorrhage, and respiratory distress) were reported in the study with no significant differences between the SC and placebo groups [24].

\section{Congenital Anomalies}

Seven publications $[16,18-21,25,27]$ that included 35 babies reported no congenital anomalies. Three RCTs $[12,24,29]$ excluded pregnancies with known fetal anomalies and, along with another RCT [23], did not report on presence or absence of fetal or congenital anomalies at birth. Consequently, these studies did not contribute to the overall rate of congenital anomalies.

\section{Stillbirth and Neonatal Death}

Fourteen studies [16-29] reported stillbirth and neonatal deaths. Overall rates of stillbirth and neonatal death were $4.3 \%$ (3/69) and 3.9\% (5/129), respectively. Whilst the specific causes for perinatal mortality were not consistently reported, rates were comparable between SC and control groups. It is likely that the rates were confounded by the effects of extreme prematurity as well as the severity of FGR and maternal PET.

\section{Discussion}

This systematic review summarises the available literature reporting clinically relevant outcomes following SC use in pregnancy. The outcomes reported in this systematic review are constrained by the paucity of studies and the limited information provided in many of these reports. Nevertheless, it appears that at the very least, maternal tolerance and perinatal outcomes following SC use in pregnancy are comparable with controls.

The available evidence so far suggests that SC is safe in pregnancy and this underpins its potential as a therapy 
for selected maternal and fetal disorders. More than 130 in vivo animal and ex vivo toxicology, pharmacology, and toxicokinetic studies have demonstrated a good safety profile for SC with no increase in teratogenic sequelae [40]. Consistent with this, no congenital anomalies were reported in our systematic review.

In terms of maternal side effects and tolerance in human pregnancy, less data is available. Information about these outcomes has largely been drawn from studies involving SC for erectile dysfunction and $\mathrm{PH}$. A review of 63 double-blind RCTs reported the safety of SC in males with erectile dysfunction for key outcomes like cardiovascular risks, visual disturbances, and tolerability with reassuring results [41]. Other studies involving males with erectile dysfunction suggest the most common side effects are those related to the pharmacology of PDE-5 inhibition and include headache, facial flushing, nasal congestion, and dyspepsia [42-45].

Maternal side effects from SC presented in our review are comparable to previously published data from nonpregnant populations $[25,26,46]$. Overall, side effects to SC in pregnancy appear mild. There was only one case in our review where a participant required an SC dose downtitration due to dyspepsia [23] and another case where the participant withdrew due to severe headache and facial flushing [24]; both of these, however, occurred in the context of PET. Such side effects also appear to be reported at similar rates in pregnant women not exposed to SC [12, $23,24,29]$ making conclusions regarding a causal effect difficult.

The obstetric and perinatal outcomes observed in this review could likely be explained by the severe maternal and fetal conditions. Amongst the studies included in this review, the indications for SC varied, as did the route, dosage, and frequency of SC administration. Overall, 165 participants received SC for PH, PET, FGR, and fertility. It is likely that the maternal and uteroplacental circulatory changes in these pregnancies could vary substantially due to different underlying pathophysiological processes. The observed stillbirth and neonatal deaths occurred at similar rates in both the SC and control groups. These were largely attributed to the severe maternal and fetal conditions which in some cases necessitated extreme premature delivery. Because of these factors, mode of delivery was often by planned CS, making firm conclusions regarding the effect of $\mathrm{SC}$ on the mode of delivery problematic. Nevertheless, the limited available data suggests that vaginal birth is not contraindicated when on SC therapy. Furthermore, the overall postpartum haemorrhage rate observed in this review was comparable to that amongst both control cohorts and the broader population [47].

The limitations of this systematic review relate mainly to the novelty of SC use in pregnancy. Although the publications included in this review reported clinically relevant outcomes, all were of small numbers and inadequately powered for rare adverse events and this remains a source of bias. Publications included in this review were limited mostly to case reports, case series, and small cohort studies, with just 3 relatively small RCTs, amongst which there was little longer-term data reported for neurodevelopmental outcomes. The included publications also did not uniformly report on all of the outcomes and this therefore limited the number of cases available for pooling of data. In some studies, outcomes were not reported for the entire cohort and consequently some studies lacked consistent, uniform reporting standards [31-35].

$\mathrm{SC}$ is amongst a number of novel therapies whose effects on improving placental function are currently being investigated. Samangaya et al. [23] were the first to document the pharmacokinetics of SC in human pregnancy in their double-blind RCT. They demonstrated that SC was metabolised more rapidly in pregnancy to its less efficacious form, desmethyl-sildenafil [23]. Some authors [10, 23 ] suggest that the altered plasma volume and $\mathrm{pH}$ in pregnancy necessitates higher doses of SC to reach a therapeutic plasma concentration. In line with this, a subsequent double-blind RCT by Trapani et al. [24] utilised a higher SC dose regimen of $50 \mathrm{mg}$ 8-hourly amongst participants with PET. When compared to placebo, they demonstrated a benefit of pregnancy prolongation as well as no worsening of maternal side effects [24]. The STRIDER study is a double-blind RCT investigating the effect SC has on improving fetal growth in pregnancies complicated by early-onset severe growth restriction [30]. Another double-blind RCT currently underway is investigating if SC administered intrapartum can reduce the risk of emergency CS for fetal compromise amongst term, appropriately grown babies [48]. Both of these studies also use an SC regimen of $50 \mathrm{mg}$ orally 8 -hourly. Further information regarding the safety profile of SC in pregnancy may be likely once these studies are published.

This review provides current information on clinically relevant outcomes following SC use during pregnancy. Overall, there does not appear to be severe adverse maternal side effects reported nor any increase in the rate of stillbirths, neonatal deaths, or congenital anomalies attributed to SC. Given the limited available information, consideration should be given to a registry-based approach for documenting outcomes of pregnancies on SC. 


\section{Acknowledgment}

This work was funded by the Mater Foundation.

\section{Disclosure Statement}

The authors report no conflicts of interest.

\section{References}

1 Mehrotra N, Gupta M, Kovar A, Meibohm B: The role of pharmacokinetics and pharmacodynamics in phosphodiesterase-5 inhibitor therapy. Int J Impot Res 2007;19:253-264.

2 Boolell M, Allen MJ, Ballard SA, Gepi-Attee S, Muirhead GJ, Naylor AM, Osterloh IH, Gingell C: Sildenafil: an orally active type 5 cyclic GMP-specific phosphodiesterase inhibitor for the treatment of penile erectile dysfunction. Int J Impot Res 1996;8:47-52.

3 Sanchez Luna M, Franco ML, Bernardo B: Therapeutic strategies in pulmonary hypertension of the newborn: where are we now? Curr Med Chem 2012;19:4640-4653.

4 Shah PS, Ohlsson A: Sildenafil for pulmonary hypertension in neonates. Cochrane Database Syst Rev 2011:CD005494.

5 Iacovidou N, Syggelou A, Fanos V, Xanthos $\mathrm{T}$ : The use of sildenafil in the treatment of persistent pulmonary hypertension of the newborn: a review of the literature. Curr Pharm Des 2012;18:3034-3045.

6 Bédard E, Dimopoulos K, Gatzoulis MA: Has there been any progress made on pregnancy outcomes among women with pulmonary arterial hypertension? Eur Heart J 2009;30:256265.

7 Običan SG, Cleary KL: Pulmonary arterial hypertension in pregnancy. Semin Perinatol 2014;38:289-294.

8 Huang S, DeSantis ERH: Treatment of pulmonary arterial hypertension in pregnancy. Am J Health Syst Pharm 2007;64:1922-1926.

9 Wareing M, Myers JE, O'Hara M, Baker PN: Sildenafil citrate (viagra) enhances vasodilatation in fetal growth restriction. J Clin Endocrinol Metab 2005;90:2550-2555.

10 Wareing M, Myers JE, O’Hara M, Kenny LC, Warren AY, Taggart MJ, Skillern L, Machin I, Baker PN: Effects of a phosphodiesterase-5 (PDE5) inhibitor on endothelium-dependent relaxation of myometrial small arteries. Am J Obstet Gynecol 2004;190:1283-1290.

11 Sher G, Fisch JD: Vaginal sildenafil (Viagra): a preliminary report of a novel method to improve uterine artery blood flow and endometrial development in patients undergoing IVF. Hum Reprod 2000;15:806-809.

12 Dastjerdi MV, Hosseini S, Bayani L: Sildenafil citrate and uteroplacental perfusion in fetal growth restriction. J Res Med Sci 2012;17: 632-636.
13 El-Far M, El-Motwally AE-G, Hashem IA, Bakry N: Biochemical role of intravaginal sildenafil citrate as a novel antiabortive agent in unexplained recurrent spontaneous miscarriage: first clinical study of four case reports from Egypt. Clin Chem Lab Med 2009; 47:1433-1438.

14 Sher G, Fisch JD: Effect of vaginal sildenafil on the outcome of in vitro fertilization (IVF) after multiple IVF failures attributed to poor endometrial development. Fertil Steril 2002; 78:1073-1076.

15 Dilworth MR, Andersson I, Renshall LJ, Cowley E, Baker P, Greenwood S, Sibley CP, Wareing $M$ : Sildenafil citrate increases fetal weight in a mouse model of fetal growth restriction with a normal vascular phenotype. PLoS One 2013;8:e77748.

16 Subbaiah M, Kumar S, Roy KK, Sharma JB, Singh N: Pregnancy outcome in women with pulmonary arterial hypertension: single-center experience from India. Arch Gynecol Obstet 2013;288:305-309.

17 Duarte AG, Thomas S, Safdar Z, Torres F, Pacheco LD, Feldman J: Management of pulmonary arterial hypertension during pregnancy: a retrospective, multicenter experience. Chest 2013;143:1330-1336.

18 Kiely DGD: Improved survival in pregnancy and pulmonary hypertension using a multiprofessional approach. BJOG 2010;117:565574.

19 Goland S, Tsai F, Habib M, Janmohamed M, Goodwin TM, Elkayam U: Favorable outcome of pregnancy with an elective use of epoprostenol and sildenafil in women with severe pulmonary hypertension. Cardiology 2010;115:205-208.

$20 \mathrm{Ng}$ WP, Yip WL: Successful maternal-foetal outcome using nitric oxide and sildenafil in pulmonary hypertension with atrial septal defect and HIV infection. Singapore Med J 2012; 53:e3-e5.

21 Molelekwa V, Akhter P, McKenna P, Bowen $\mathrm{M}$, Walsh K: Eisenmenger's syndrome in a 27 week pregnancy-management with bosentan and sildenafil. Ir Med J 2005;98:87-88.

22 Lacassie HJ, Germain AM, Valdes G, Fernandez MS, Allamand F, López H: Management of Eisenmenger syndrome in pregnancy with sildenafil and L-arginine. Obstet Gynecol 2004;103:1118-1120.
23 Samangaya RA, Mires G, Shennan A, Skillern L, Howe D, McLeod A, Baker PN: A randomised, double-blinded, placebo-controlled study of the phosphodiesterase type 5 inhibitor sildenafil for the treatment of preeclampsia. Hypertens Pregnancy 2009;28:369-382.

24 Trapani A Jr, Goncalves LF, Trapani TF, Vieira S, Pires M, Pires MM: Perinatal and hemodynamic evaluation of sildenafil citrate for preeclampsia treatment: a randomized controlled trial. Obstet Gynecol 2016;128:253259

25 El-Far M, Hashem IMA: Novel biopharmaceutical use of sildenafil citrate in treatment of unexplained recurrent miscarriage: first longitudinal clinical study of 50 cases from Egypt. World J Pharm Pharmaceut Sci 2014;3:63-86.

26 von Dadelszen P, Dwinnell S, Magee LA, Carleton BC, Gruslin A, Lee B, Lim KI, Liston RM, Miller SP, Rurak D, Sherlock RL, Skoll MA, Wareing MM, Baker PN; Research into Advanced Fetal Diagnosis and Therapy (RAFT) Group: Sildenafil citrate therapy for severe early-onset intrauterine growth restriction. BJOG 2011;118:624-628.

27 Panda S, Das A, Nowroz HM: Sildenafil citrate in fetal growth restriction. J Reprod Infertil 2014;15:168.

28 Lin T, Su Y, Shih J, Hsu H, Lee C: Resolution of high uterine artery pulsatility index and notching following sildenafil citrate treatment in a growth囚restricted pregnancy. Ultrasound Obstet Gynecol 2012;40:609-610.

29 Trapani A, Gonçalves LF, Trapani TF, Franco MJ, Galluzzo RN, Pires MMS: Comparison between transdermal nitroglycerin and sildenafil citrate in intrauterine growth restriction: effects on uterine, umbilical and fetal middle cerebral artery pulsatility indices. Ultrasound Obstet Gynecol 2016;48:61-65.

30 Ganzevoort W, Alfirevic Z, von Dadelszen P, Kenny L, Papageorghiou A, van WassenaerLeemhuis A, Gluud C, Mol BW, Baker PN: STRIDER: Sildenafil therapy in dismal prognosis early-onset intrauterine growth restriction - a protocol for a systematic review with individual participant data and aggregate data meta-analysis and trial sequential analysis. Syst Rev 2014;3:23.

31 Gagnier JJ, Kienle G, Altman DG, Moher D, Sox H, Riley D: The care guidelines: consensus-based clinical case reporting guideline development. Headache 2013;53:1541-1547. 
32 von Elm E, Altman DG, Egger M, Pocock SJ, Gøtzsche PC, Vandenbroucke JP: The strengthening the reporting of observational studies in epidemiology (strobe) statement: guidelines for reporting observational studies. Prev Med 2007;45:247-251.

33 Moher D, Schulz KF, Altman DG: The CONSORT statement: revised recommendations for improving the quality of reports of parallel-group randomised trials. Lancet 2001;357: 1191-1194.

34 Moher D, Liberati A, Tetzlaff J, Altman DG; PRISMA Group: Preferred reporting items for systematic reviews and meta-analyses: the PRISMA statement. Ann Intern Med 2009; 151:264-269.

35 Carey TS, Boden SD: A critical guide to case series reports. Spine 2003;28:1631-1634.

36 Bao Z, Zhang J, Yang D, Xu X: Analysis of high risk factors for patient death and its clinical characteristics on pregnancy associated with pulmonary arterial hypertension. Zhonghua Fu Chan Ke Za Zhi 2014;49:495-500.

37 Sun X, Wang K, Wang W, Li B: Clinical study on sildenafil in treatment of pregnant women with pulmonary arterial hypertension. Zhonghua Fu Chan Ke Za Zhi 2014;49:414-418.

38 Malinova M: Sildenafil - for treatment of preeclampsia and intrauterine growth restriction. Akush Ginekol (Sofiia) 2013;53:40-43.
39 Taçoy G, Ekim NN, Çengel A: Dramatic response of a patient with pregnancy induced idiopathic pulmonary arterial hypertension to sildenafil treatment. J Obstet Gynaecol Res 2010;36:414-417.

40 Abbott D, Comby P, Charuel C, Graepel P, Hanton G, Leblanc B, Lodola A, Longeart L, Paulus G, Peters C, Stadler J: Preclinical safety profile of sildenafil. Int J Impot Res 2004; 16: 498-504.

41 Giuliano F, Jackson G, Montorsi F, MartinMorales A, Raillard P: Safety of sildenafil citrate: review of 67 double-blind placebo-controlled trials and the postmarketing safety database. Int J Clin Pract 2010;64:240-255.

42 Gresser U, Gleiter C: Erectile dysfunction: comparison of efficacy and side effects of the PDE-5 inhibitors sildenafil, vardenafil and tadalafil - review of the literature. Eur J Med Res 2002;7:435-446.

43 Brock GB, McMahon CG, Chen K, Costigan T, Shen W, Watkins V, Anglin G, Whitaker S: Efficacy and safety of tadalafil for the treatment of erectile dysfunction: results of integrated analyses. J Urol 2002;168:1332-1336.
44 Hellstrom WJ, Gittelman M, Karlin G, Segerson T, Thibonnier M, Taylor T, PadmaNathan $\mathrm{H}$ : Vardenafil for treatment of men with erectile dysfunction: efficacy and safety in a randomized, double-blind, placebo-controlled trial. J Androl 2002;23:763-771.

45 Hellstrom WJ, Gittelman M, Karlin G, Segerson T, Thibonnier M, Taylor T, Padma-Nathan H, Group VS: Sustained efficacy and tolerability of vardenafil, a highly potent selective phosphodiesterase type 5 inhibitor, in men with erectile dysfunction: results of a randomized, double-blind, 26-week placebocontrolled pivotal trial. Urology 2003;61:814.

46 Galiè N, Ghofrani HA, Torbicki A, Barst RJ, Rubin LJ, Badesch D, Fleming T, Parpia T, Burgess G, Branzi A: Sildenafil citrate therapy for pulmonary arterial hypertension. N Engl J Med 2005;353:2148-2157.

47 Ford JB, Patterson JA, Seeho SKM, Roberts CL: Trends and outcomes of postpartum haemorrhage, 2003-2011. BMC Pregnancy Childbirth 2015;15:334.

48 Dunn L, Flenady V, Kumar S: Reducing the risk of fetal distress with sildenafil study (RIDSTRESS): a double-blind randomised control trial. J Transl Med 2016;14:15. 